\title{
DIREITO, DIGNIDADE HUMANA E SAÚDE PÚBLICA - UMA ANÁLISE SOBRE A SAÚDE NACIONAL E A INFLUÊNCIA DO CAPITAL PARA PRESERVAÇÃO DA VIDA
}

\author{
LAW, HUMAN DIGNITY AND PUBLIC HEALTH - AN ANALYSIS ON NATIONAL HEALTH AND
} THE INFLUENCE OF CAPITAL FOR LIFE PRESERVATION

Antonio Augusto VILELA ${ }^{1}$

ISSUE DOI: $10.21207 / 1983.4225 .700$

\begin{abstract}
RESUMO
Um dos principais fatores para a existência do homem no mundo é a sua luta constante com o seu próprio corpo, assim sendo, com a sua própria saúde. Percebe-se que a sua concepção seria a característica do que é sadio ou são, ainda neste contexto, se tem também que é o adequado estado do organismo de um ser vivo, o qual possuiu funções regulares, visando assim a prolongar seus anos de vida. O que garante isso é a efetivação de novos meios de cuidados e tratamentos, que beneficiem a todos os cidadãos, com uma mera gratuidade abstrata, na perspectiva de que, todos recebem um excelente tratamento quando necessário, e não especificamente, uma pequena parte da população, classe dominante. A política pública da saúde não pode apresentar-se apenas como uma disposição usada pela classe dominante de manterem-se submissas as demais classes, relevando-se assim, as características da infra e a superestrutura social. No Brasil, existe o Sistema Único de Saúde (SUS), no qual a Legislação garante direitos para proteger a saúde de todos os cidadãos com uma garantia abstrata, pois na realidade muitos dispositivos legais não são respeitados.
\end{abstract}

Palavras-chave: Direito, Dignidade humana, saúde pública

\footnotetext{
${ }^{1}$ Graduação em Direito em 2015 na Fundação Carmelitana Mário Palmério (FUCAMP), Monte Carmelo/MG. Graduação em Administração em 2010 na Faculdade Cidade de Coromandel, FCC/AEC, Coromandel/MG. Especialização em Direito de Família e Sucessões em 2017 pela Faculdade de Direito Prof. Damásio de Jesus, FDDJ, Brasil. Especialização em Direito Previdenciário em 2018 pela Faculdade de Direito Prof. Damásio de Jesus, FDDJ. http://lattes.cnpq.br/9929841808307002
} 


\begin{abstract}
One of the main factors for the existence of man in the world is his constant struggle with his own body, and thus with his own health. It is perceived that its conception would be the characteristic of what is healthy or healthy, even in this context, if it also has to be the appropriate state of the organism of a living being, which had regular functions, thus aiming to prolong its life years. . What guarantees this is the implementation of new means of care and treatment that benefit all citizens, with a mere abstract gratuity, in the perspective that everyone receives excellent treatment when necessary, and not specifically, a small part of the population., ruling class. Public health policy can not only be presented as a disposition used by the ruling class to remain submissive to other classes, thus highlighting the characteristics of the infra and the social superstructure. In Brazil, there is the Unified Health System (SUS), in which the Legislation guarantees rights to protect the health of all citizens with an abstract guarantee, because in reality many legal provisions are not respected.
\end{abstract}

Keywords: Law, Human dignity, Public health.

\title{
INTRODUÇÃO
}

Um dos principais fatores para a existência do homem no mundo é a sua luta constante com o seu próprio corpo, assim sendo, com a sua própria saúde. Percebe-se que a sua concepção seria a característica do que é sadio ou são, ainda neste contexto, se tem também que é o adequado estado do organismo de um ser vivo, o qual possuiu funções regulares, visando assim a prolongar seus anos de vida. O que garante isso é a efetivação de novos meios de cuidados e tratamentos, que beneficiem a todos os cidadãos, com uma mera gratuidade abstrata, na perspectiva de que, todos recebem um excelente tratamento quando necessário, e não especificamente, uma pequena parte da população, classe dominante. A política pública da saúde não pode apresentar-se apenas como uma disposição usada pela classe dominante de manterem-se submissas as demais classes, relevando-se assim, as características da infra e a superestrutura social.

No Brasil, existe o Sistema Único de Saúde (SUS), no qual a Legislação garante direitos para proteger a saúde de todos os cidadãos com uma garantia abstrata, pois na realidade muitos dispositivos legais não são respeitados.

Portanto, a relativa importância da Medicina institucionalizada dentro do setor de saúde vem diminuindo. Uma mistura curiosa de práticas de auto-cuidado, ao mesmo tempo opinativas e detalhadas, juntas com um entusiasmo ingênuo pelas tecnologias sofisticadas, tornam os esforços e atenção pessoal dos médicos cada vez mais 
frustrante. Suspeito que a contribuição da Medicina à busca patogênica da saúde é um fator menor hoje em dia. (ILLICH, 1975, p.212)

Nesse contexto, ainda se observa que no Brasil, devido a grande desigualdade social ainda existente, embora a Constituição Federal pregue igualdade entre todos, há certa abstração no cumprimento de tal dever do Estado. Observa-se que as principais atividades voltadas para a saúde são precárias, o poder do capital, ainda nas mãos de poucos, é responsável a cada dia, pelo problema concreto enfrentado por grande parte da população: o aumento de filas para atendimento, o valor elevado de medicamentos, a falta de equipamentos necessários para a boa atuação dos profissionais da saúde. Essas mazelas determinam a exploração da classe trabalhadora pela classe dominante, tornando o individuo escravo do capital. A precarização da saúde prestada pelo Estado ainda necessita de uma grande observação, a classe dominante, encontra novos meios de exploração fazendo com que a economia empresarial de exploração, se mantenha até sobre as enfermidades dos indivíduos, pois poucos tem acesso aos planos de saúde particulares.

O Estado, esquecendo-se de incentivar e proporcionar políticas públicas nas quais, atribuam valoração a qualidade de vida dos indivíduos, tem criado uma grande mazela social. Como diria CANEQUI (1982) Apud PEREIRA e ÁVILA, 2001: "na ausência de uma política pública para atender a procura das pessoas e dos casais por métodos contraceptivos, o mercado (farmácias, rede de saúde e outras instituições privadas) passaram a ocupar este espaço". (CANEQUI (1982) Apud PEREIRA e ÁVILA, 2001 p.04)

O capitalista, fascinado com os fetiches que o capital pode trazer, usou mais esse artifício para conseguir lucros e explorar os desejos mais oiriçados da classe dominada.

Pela amplitude da temática, buscou-se analisar a dignidade da pessoa humana em relação à manutenção do Estado e instituição da propriedade privada dos meios de produção, com os interesses sociais em disputa. Embora existam leis que institua a saúde pública como direito universal, as normas positivadas carecem de maior concretização.

A saúde dos indivíduos necessita de uma observação cada vez mais acurada, pois a busca particularizada de riquezas para ampliar o capital e a exploração da classe dominada em todos os níveis sociais são fatores que levam a refletir sobre o que fazer para ter uma saúde de qualidade com 
dignidade. A conscientização do fator governamental, essencial para a qualificação da saúde, grande parte das vezes deixa a desejar, pois somente a classe dominante tem os melhores métodos e artifícios para permanecer saudável. Isso faz com que a divisão desigual da renda beneficie os grandes capitalistas, esquecendo-se do fator essencial, a saúde e a dignidade da pessoa humana.

\section{OBJETIVOS}

\subsection{OBJETIVO GERAL}

Identificar a influência do capital na qualidade da saúde dos indivíduos.

\subsection{OBJETIVOS ESPECÍFICOS}

- Demonstrar a luta dos indivíduos, e o quanto o capital influencia na qualidade da saúde dos indivíduos;

- Relacionar desenvolvimento do capitalismo e sua exploração até na luta do homem contra a sua própria natureza;

- Estabelecer a função do Estado/Direito na regulação da relação capital/saúde

\section{JUSTIFICATIVA}

É de grande importância para os indivíduos ter uma qualidade digna de saúde, na qual, todos vivam e se relacionam bem no seio social. "As necessidades de saúde da população são sentidas por todos e estão representadas nos altos índices de mortalidade, morbidade..., como também na baixa expectativa de vida do povo brasileiro." (GONÇALVES, 1995, p.01) 
O presente trabalho justifica-se por três grandes metas a serem estabelecidas socialmente: a conservação da dignidade da saúde humana, o fator capital influenciador na saúde dos cidadãos, a qualidade de saúde sendo restritiva apenas para alguns.

Para a ciência jurídica é de suma importância o estudo das questões ligadas ao cumprimento do direito voltado para a saúde digna dos cidadãos, porque o mundo está em constante desenvolvimento e as gerações futuras necessitam de garantias de uma vida condignas.

Saúde, assim, por outro lado, definida de forma menos abrangente, depende de educação, de condições de trabalho, de condições financeiras, de condições de conforto físico... Cada uma destas variáveis se liga à outra de maneira irreversível, uma vez que, educado, o individuo tem possibilidade de conseguir um emprego que lhe dê acesso a condições financeiras. Estas permitem que o individuo compre serviços de saúde e conforto físico. Com a saúde, é mais fácil obter educação e emprego. Mesmo por esta visão, extremamente simplista, passa a ser difícil ignorar que todas estas variáveis estão diretamente envolvidas no desenvolvimento. (GONÇALVES, 1995, p.05)

O presente trabalho justifica-se pela necessidade de analisar a qualidade da saúde nacional. O Estado deve cumprir seu dever, de maneira que as regras abstratas se efetivem, não se deixando levar pela influência do capital e pela relação materialista com a manutenção Estatal acima da dignidade individual. Neste contexto, a saúde deve ser valorizada como um bem jurídico, supremo, garantida constitucionalmente e que precisa de cuidados e uma observação constante. Assim, o Direito, que a cada dia vem se modificando e evoluindo, deveria contribuir para que uma Justiça abstrata voltada para a saúde seja fator primordial para a conservação da dignidade da pessoa humana. Contudo observa-se que a conservação da saúde humana envolve fatores ainda maiores: os detentores do poder econômico influenciam constantemente na tomada de decisões, fazendo com que parte da população permaneça alienada, e grande parte dos indivíduos pensem só no presente momento, deixando de lado, a preocupação com a qualidade da saúde no futuro. Para esse fim será observado o quanto a conscientização do ser humano é importante para que se tenha uma saúde com dignidade, garantida pelo Estado. Os cidadãos necessitam de conscientizar que seus direitos não são apenas utopia destruída constantemente pela influência do capital. A saúde deve ser vista e revista como um fator primordial e a sua efetivação deve ser garantida universalmente de forma digna. 


\section{METODOLOGIA}

O presente trabalho desenvolveu-se com base em uma pesquisa qualitativa, voltando assim, todo o embasamento teórico para a crítica da saúde digna dos cidadãos.

Essa breve análise sintética pretende:

Compreende um conjunto de diferentes técnicas interpretativas que visam descrever e a decodificar os componentes de um sistema complexo de significados. Tem por objetivo traduzir e expressar o sentido dos fenômenos do mundo social; trata-se de reduzir a distância entre e indicado, entre teoria e dados, entre contexto e ação. (MAANEN, John Van. (1979) apud NEVES, 2005, p. 03)

Observando a temática e buscando relatar elementos importantes para o estudo em geral usou-se a pesquisa bibliográfica. A pesquisa decorreu-se de um processo sistemático de construção do conhecimento que tem como metas principais gerar novas perspectivas de conhecimento e/ou refutar algum conhecimento pré-existente. As obras que analisadas são, respectivamente, nas áreas da Saúde, Direito e Dignidade da Pessoa Humana. Também foram consultadas revistas e sites especializados na amplitude da temática, observando inicialmente, o poder governamental e o quanto a busca cada vez maior de capital, tem influenciado de forma subliminar para a dignidade da pessoa humana, mais especificamente interferindo na saúde dos cidadãos. Severino afirma que: "em primeiro lugar, é preciso que o estudante se conscientize de que doravante o resultado do processo depende fundamentalmente dele mesmo". (SEVERINO, 1996, p.25)

Deve-se ressaltar ainda que o estudo considerou e observou apenas os elementos pesquisados, portanto, as conclusões obtidas não podem ser generalizadas. A observância desses elementos deve-se ao fato de serem essenciais para a saúde, bem-estar/dignidade da população.

\section{FUNDAMENTAÇÃO TEÓRICA}

\subsection{O CAPITAL E A SUA INFLUÊNCIA NA QUALIDADE DA SAÚDE DOS INDIVÍDUOS}


O capital tem sido um grande vilão da saúde dos indivíduos nos dias atuais, observado através da perspectiva do trabalho, no qual sendo ressaltado como a infelicidade a ser o instituidor de "valor-de-uso é indispensável à existência da sociedade humana" (MARX, 2002, p. 60). O indivíduo em quaisquer sociedades impugnará ao trabalho agilidade intercessora entre homem e o seu estado natural para abastecer a sua sobrevivência. O indivíduo trabalhador transforma a natureza através de seus afazeres. Ao transformar a natureza depositam em movimento as aptidões de seu conveniente corpo ao que, no agir do procedimento de trabalho no caráter de produção capitalista depara-se com utensílios de afazeres altamente desenvolvidos. Promover ou abater o empenho do indivíduo trabalhador no procedimento de trabalho necessitaria ser a fundamental finalidade do aumento dos novos artifícios usados pelo homem trabalhador, entretanto, no caráter de fabricação capitalista, tem-se a conexão, o proletário contornase apenas uma continuação do processo da máquina, pois é indivíduo que deve se combinar ao aparato do bem-sucedido.

Graças ao progresso da produtividade do trabalho social, quantidade sempre crescente de meios de produção pode ser mobilizada com um dispêndio progressivamente menor de força humana. Este enunciado é uma lei na sociedade capitalista, onde o instrumental de trabalho emprega o trabalhador, e não este o instrumental [...]. (MARX, 2002, p. 748)

Diante dessa observação, compreendemos que a maneira de produção capitalista apresenta uma conexão oportuna em que, grande parte das vezes é representada pela luta do homem contra a sua própria natureza, observando as suas necessidades e influenciada diretamente pela classe dominante a buscar novos meios de exploração no qual, empreendem em todos os meios sociais. Essa luta marcada de interesses observa-se que nem sempre os meios apresentam aos cidadãos, quando necessário uma boa qualidade de tratamento e também os artifícios usados para conseguir uma saúde digna. Dentro desse paradigma observa-se o valor do capital sendo maior do que o valor da própria vida humana, esquecendo-se a garantia constitucional. A dignidade da pessoa humana está relacionada intrinsicamente com uma boa qualidade de saúde prestada a todos os cidadãos.

Através das disposições legais na qual o governo coloca-se a favor da sociedade para que se tenha uma saúde de qualidade e respeitosa a todos, a classe dominante, observando algumas mazelas no sistema, aproveita de tal situação e usa desses meios para conseguir seus objetivos. A 
necessidade de uma saúde com eficiência e com qualidade levada aos cidadãos em várias situações não se faz de forma digna, por não poderem pagar tratamento particular recorrem a hospitais públicos, que não sendo atendidos prontamente por falta de vagas ou de profissionais, acabam falecendo.

Observa-se cotidianamente que as filas de hospitais públicos, e outros meios que buscam resultados a uma vida saudável, cada vez mais de difícil acesso, pois cada vez mais estão lotados; no entanto aqueles que possuem o valor capital, tem melhores condições de vida e uma saúde digna. A sociedade capitalista não oculte as relações de exploração e de:

[...] fórmulas que pertencem, claramente, a uma formação em que o processo de produção domina o homem, e não o homem o processo de produção, [assim,] são consideradas pela consciência burguesa uma necessidade tão natural quanto o próprio trabalho produtivo (MARX, 2002, p. 102).

Indivíduos no sistema capitalismo são alienados a uma existência reificada, alimentada de intricadas fantasias das sociedades, que colocam valores, costumes e jeitos de se ser, nos quais, agregam a negação de se colocar o valor do trabalho/capital acima de todas as coisas. O capital é usado sempre para apropriação de novos bens e serviços, e o valor de troca, até para os benefícios da saúde digna dos seres humanos. Como mera mercadoria de exploração dos capitalistas que impõem valor até nos meios e recursos para a produção de uma vida saudável.

Observando esses pressupostos de análise, compreendemos, portanto, que a discussão sobre saúde torna-se pertinente, visto que, a dignidade da pessoa humana esta ligada diretamente a esse princípio. Quando se realiza uma observação de forma crítica e com o objetivo de desenvolver argumentos para uma boa parte dos indivíduos tem carência de uma prestação de serviço com qualidade, e não tem condições de pagar valores elevados. Empresários/classe dominante negam radicalmente as mudanças nas condições vigentes de saúde/vida dentro e fora de um sistema.

Sendo assim, a população em geral, fica a mercê de um mero sistema de saúde, cheio de mazelas, e de grande precariedade, por falta de não se ter um valor representativo de capital, para oferecer aos empresários/classe dominante dos meios de saúde; cabe ao Estado uma eficácia maior na área de prestação de serviços ligada a saúde dos cidadãos, observando a dignidade da pessoa humana, quesito essencial para a vida. A saúde é, antes de tudo, uma questão política e econômica, uma vez que o 
enfrentamento do problema passa por uma total reviravolta na política econômica que rege o sistema. $\mathrm{O}$ poder do Estado deveria se apresentar de forma eficiente, contra a não alienação dos artifícios a favor da saúde/vida, e a não posse de uma mera apresentação da mídia na qual se dispõe que tudo ocorre bem e que a saúde de todos os seres humanos está equilibrada e sendo cuidada através de tratamentos dignos e necessários para a preservação da vida de todos os cidadãos.

\subsection{CAPITALISMOS E SUA EXPLORAÇÃO ATEM NA LUTA DO HOMEM CONTRA A SUA PRÓPRIA NATUREZA}

No inicio da sociedade quando o ser humano tinha diante de si apenas uma mínima perspectiva sobre o quanto era importante para todos os indivíduos, a luta de si próprios contra a sua própria natureza, começava nascer um interesse no seio social, os paradigmas eram modificados, novas idealizações de trabalho surgiram como um objeto de utilidade; não era necessariamente um valor de troca, era um bem comum, não social.

Pouco a pouco, com o progresso veio crescendo os problemas de saúde dos indivíduos, e a saúde se tornou um instrumento de grande valor comercial, nascia desde então, uma forma de exploração, ocorrida através da boa conservação da saúde dos mesmos; que, em suma, é o ponto de partida do capitalismo, na qual, pretende-se abordar a partir deste ponto o seu desenvolvimento e a valoração de uma saúde digna e com qualidade.

Com o advento da Revolução Industrial, os indivíduos começaram a sofrer uma série de mudanças radicais que deram início a uma exploração acentuada do homem pelo próprio homem. Também observa-se uma transformação gradativa, que apontaram para uma necessidade dos indivíduos se preocuparem com uma saúde digna, na qual, não se dava muita relevância, devido ao grande tempo trabalhado em condições insalubres e a força de trabalho aplicada ao extremo em grandes partes dos setores que os indivíduos trabalharam. Os indivíduos começaram a refletir que a saúde estava sendo deixada de lado, para a busca cada vez maior de capital.

Dessa forma o capitalismo tomou força e a classe dominante precisava construir uma ideologia para que mantivesse a usufruir do trabalho dos indivíduos, a exploração, gerou a criação dos direitos impostos para beneficiar a todos os cidadãos com igualdade. 
A igualdade perante a lei tem pouco significado se não existir sufrágio universal e outras chances de participação política. As chances de participação são apenas uma promessa vazia se as pessoas não têm a posição social e econômica que as coloque em condições de gozar daquilo que as leis e a constituição lhes prometem. Passo a passo, a idéia de cidadania foi dotada de conteúdo. De uma quantidade formal de direitos, a cidadania tornou-se um status, de que fazem parte, além do direito eleitoral, uma renda digna e o direito a ter uma vida civil, inclusive quando se está doente, ou velho, ou desempregado (DAHRENDORF, 1987. Apud. LOSURDO, 2002 p. 27).

Nesse ínterim observa-se que é pouca uma teodiceia da felicidade, a qual, os dominadores, os detentores, os vitoriosos, os sãos, em síntese, o conhecido, como homem feliz que raramente se satisfazem pelo ingênuo fato de ser dono da oportuna prosperidade; no modo de produção capitalista, a ideologia gerada e que, todos os homens tem por direito, serem felizes. A felicidade abstrata, assim sendo, é percebida diante de que: "quer ser convencido de "merecê-la" e sobretudo de merecê-la frente aos outros. E quer portanto ser também autorizado a crer que os de menos sorte receberam equitativamente apenas aquilo que lhes cabe. A felicidade quer ser "legítima"'. (LOSURDO, 2002. p. 05)

Observando esse paradigma, o homem que tem a felicidade, no sistema capitalista, é aquele possuidor dos meios de produção, que detêm determinados meios para explorar, idealizando aos indivíduos uma perspectiva de liberdade dada através do direito, a todos os cidadãos de forma igualitária.

\footnotetext{
Quando se fala de "capitalismo", pensa-se em capital e sobretudo em capitalista, sujeito rico, poderoso, em geral dono ou dirigente de empresa industrial, comercial ou banco. Mas "capitalismo" sugere também enorme variedade de produtos que são estridentes mente propagandeados pelos meios de comunicação em massa. Os símbolos atuais deste aspecto capitalismo talvez sejam o automóvel e principalmente a televisão, que é meio de consumo e veiculo de publicidade ao mesmo tempo (SINGER, 1987, p. 7).
}

Por ser um sistema constitucionalmente explorador, destruidor e causador de desigualdades, em que uma classe dominadora é possuidora dos meios de produção e das riquezas produzidas, o capitalismo se desenvolve em uma perspectiva avassaladora. Em determinados acontecimentos a desconsideração com a saúde dos indivíduos é tamanha, deixando de lado os valores necessários como boa alimentação, descanso físico/psicológico, 
lazer, etc; decorrida da exploração da força de trabalho realizada pelo individuo.

[...] os desgraçados que fazem os trabalhos pesados, produtores dos gozos alheios, que recebem apenas para a subsistência de seus corpos sofridos e necessitados de tudo, esta multidão imensa de instrumentos bípedes sem liberdade, sem moral, sem faculdade intelectual, dotados apenas de mãos que recebem pouco e de uma mente gravada por mil preocupações que os fazem apenas sofrer [...] são estes que vocês chamam homens? São considerados civilizados, mas alguém já viu, pelo menos um desses, que fosse capaz de entrar na sociedade? (LOSURDO, 2002. p. 10)

No ponto de vista estritamente socioecológico, percebe-se que os problemas são resultantes do modo da produção capitalista, observando o fato de que, o desenvolvimento da economia capitalista concentra-se na exploração da força de trabalho humana na qual, simultaneamente, e em grande parte da vezes, destrói de forma voraz a saúde digna dos cidadãos.

Portanto, durante essa breve analise, conclui-se que o capitalismo pode ser considerado uma espécie de parasita social, o qual, age como uma força destruidora/ativa, que explora e faz os indivíduos se adequarem a uma desleal forma de ser, destruindo progressivamente sua saúde, sua felicidade e por findar as suas vidas, assegurando-se a todos homens, que dinheiro conseguido de forma leal, seja uma mera abstração para aos seus fetiches e liberdades individuais.

\subsection{A FUNÇÃO DO ESTADO/DIREITO NA REGULAÇÃO DA RELAÇÃO CAPITAL/SAÚDE}

Um dos problemas mais questionados e enfrentados no Brasil diz respeito a saúde, visto que o Brasil tem um valor significativo de cidadãos que necessitam direta ou indiretamente de métodos que envolvam o beneficio à saúde.

Convém ressaltar que ao se negar e superar aspectos da realidade objetiva anterior, a obtenção de uma nova qualidade, a qualidade anterior é negada, suprimida e eliminada, mas não é simplesmente aniquilada, não desaparece sem deixar marcas. Pelo contrário, nesta negação preserva-se anterior resultado positivo do desenvolvimento subsequente. (HAHN \& ROSING, 1983, p. 73) 
O ser humano, sofreu doenças que foram surgindo no decorrer do tempo, e com a falta de medicamentos e tratamentos. Esses estragos se estenderam gradativamente, o Estado teve que tomar uma decisão na qual beneficiasse a todos com dignidade.

Atualmente, a preocupação com a proteção a saúde é vista como o bem de maior importância para toda a sociedade. Os indivíduos estão percebendo, cada vez mais a necessidade de se ter uma saúde de qualidade e digna, na qual o Estado é comprometido a prestar aos cidadãos, sem discriminação e imposta através de leis, que supram as relações jurídicas sociais nas quais, são garantidas abstratamente pelo Estado, e compreendidas assim, por serem idealizada como as raízes das relações materialistas.

\begin{abstract}
Minha pesquisa chegou à conclusão que as relações jurídicas, bem como as formas do Estado, não podem ser compreendidas por si só, nem pela assim chamada evolução geral do espírito humano, mas têm suas raízes nas relações materiais da existência - cujo conjunto Hegel inclui no termo de sociedade civil, seguindo o exemplo dos ingleses e franceses do século XVIII - e que a anatomia da sociedade civil deve ser procurada na economia política. (MARX, 1983, p. 301)
\end{abstract}

Assim, observa-se que a base de materialização social, é percebida em sua essência pelo Estado, e que tais raízes, são uma mera abstração para a manutenção de um sistema cheio de mazelas; ao qual, a comunidade, participando diretamente através de representantes, o Governo brasileiro, proclamou em meados do ano de 1990 a Lei ${ }^{\circ}$ 8.080, que passou a dispor de um instrumento legal de proteção a saúde dos indivíduos, com a criação do Sistema Único de Saúde, nasceu consigo a esperança de se ter uma saúde digna. No mesmo ano nascia para acolher os anseios sociais, a Lei ${ }^{\circ}$ 8.142, que dispõe sobre a participação da comunidade na gestão do Sistema Único de Saúde e sobre as transferências intergovernamentais de recursos financeiros na área da saúde e dá outras providências, em vigor até hoje. Para Hahan e Rosing "[...] as leis fundamentais da dialética materialista abrangem conexões do próprio mundo material, conexões que existem fora da consciência humana e independem dela". (HAHN E ROSING, 1983. p.66)

A Lei, além de dar certa segurança aos cidadãos, dando-lhes uma perspectiva de uma saúde de qualidade, a proteção e garantia do Estado na dignidade da pessoa observada através da referida saúde de todos homens, visa também assegurar que tratamentos, medicamentos, e outros meios de tratamento, sejam feitos com racionalidade e gratuitamente. Um grande 
avanço, principalmente numa época em que a visão era a de não preocupação com a saúde da população.

Essas mesmas leis estabeleceram a criação de Conferência da saúde, o Conselho de saúde do Fundo Nacional de Saúde, o qual será utilizada em despesas de custeio e de capital do Ministério da Saúde, ambas criadas em 1990.

O Art. 196 da Constituição do Brasil de 1988 coloca a questão saúde na forma que se segue: "A saúde é direito de todos e dever do Estado, garantido mediante políticas sociais e econômicas que visem à redução do risco de doença e de outros agravos e ao acesso universal e igualitário às ações e serviços para sua promoção, proteção e recuperação."

Vale destacar que a legislação brasileira é considerada avançada em muitos aspectos, no entanto apresenta um caráter de bastante observação para o Estado. Vários crimes cometidos contra a saúde dos indivíduos ainda ficam impunes devido ao pequeno número de fiscais em relação à extensão do território brasileiro.

Portando percebe-se que, embora a Constituição de 1988 significa que um avanço na legislação e gestão administrativa pública voltada para saúde do país, o caminho ainda é longo e está em constante construção. Enquanto não houver conscientização política coletiva, não haverá cobrança de direitos.

\section{CONSIDERAÇÕES FINAIS}

Com objetivo de finalização deste trabalho, foi proposta uma análise embasada em concepções críticas a saúde nacional e verificou-se o quanto esse sistema é prejudicial não só para o homem como a todos do seio social, mas também para a saúde dos indivíduos, em decorrência da grande ganância pelo capital e o aumento dos bens.

Percebe-se que a saúde nacional está passando por grandes mazelas que são decorrentes das sucessivas crises do capitalismo que se representam diretamente na sociedade, tomando proporções em grande escala devido à precariedade do país, que faz com que o cidadão seja tratado de forma desmerecedora, sem dignidade e sem um mínimo de preocupação. 
O Estado deveria fazer as regras se efetivarem para proteger a saúde de todos com dignidade. A criação de um Sistema Único de Saúde foi de grande representação, mas sua eficácia é deficiente pela falta de estrutura do Estado e também pela influência do capital, que é resultante do processo de circulação de mercadorias, tendo valores agregados de acordo com o seu processo de conversão em valores de uso. De fato o indivíduo na contemporaneidade está excessivamente ligado na base material/econômica da sociedade, na qual, Karl Marx denomina por infraestrutura, assim sendo, usa a supra estrutura, que é uma ideologia para justificar a dominação de todos os meios sociais.

Enfim, é fundamental o Estado assegurar a saúde de forma digna, com direito universal, para todos independente de sua classe social. A qualidade da saúde dos indivíduos, não deve ser apenas uma forma de mercadoria social, e sim uma questão de valor social essencial à sobrevivência da espécie humana.

\section{REFERÊNCIAS}

BERQUÓ, E. ; CAVENAGUI, S. Mapeamento socioeconômico e demográfico dos regimes de fecundidade no Brasil e sua variação entre 1991 e 2000. Disponível em: <www.nepo.unicamp.br/aulas/2010/mapeamentosocioeconomico.pdf>. Acesso em: abril. 2012.

BRASIL. Constituição Republica Federativa do Brasil. Brasília: Ministério da Educação, 1988.

CANEQUI (1982) Apud PEREIRA, Antonio Luis Correa. ÁVILA, Maria Antonieta Nunes de. Planejamento familiar no brasil - uma análise crítica. 2001. P.04

DAHRENDORF, R. (1987). Apud. LOSURDO, Domenico. Marx, a tradição liberal e a construção histórica do conceito universal de homem. 2002. p. 05.p.10 p. 27

GONÇALVES, Ernesto Lima. Administração de saúde no Brasil. Gráfica Editora Bisordi Ltda. São Paulo - 1996

HAHN, E. e KOSING, A. A filosofia marxista lenista: curso básico. Lisboa: Avante, 1983.

ILLICH, I. A expropriação da saúde. Nêmesis da Medicina. Rio de Janeiro: Nova Fronteira, 1975.

MAANEN, John Van. (1979) Apud NEVES, José Luis. Pesquisas qualitativas - características, usos e possibilidades. 2005. P. 03

MARX, Karl, e, ENGELS, Friedrich. Obras escolhidas I, II e III. São Paulo: Editora Alfa-Omega, 1983. 
MARX, Karl. O capital: crítica da economia política. Tradução de Reginaldo Sant'Anna. Rio de Janeiro: Civilização Brasileira, 2002. Livro I, v. 1e v. 2.

ROCHA, Ruth. Minidicionário. São Paulo: Scipione. 1996.

SEVERINO, Antonio Joaquim. Metodologia do trabalho cientifico. 20. ed. São Paulo: Cortez, 1996.

SINGER, Paul. O capitalismo: sua evolução, sua lógica e sua dinâmica. São Paulo: Moderna, 1987.

SIEYÈS, E. J. (1985) Apud. LOSURDO, DOMENICO. Marx, a tradição liberal e a construção histórica do conceito universal de homem. 2002. 